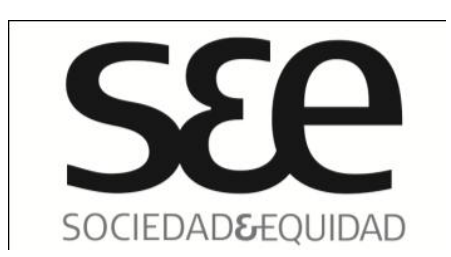

SOCIEDADEEQUIDAD

\section{Memorias colectivas, resistencias y movimientos sociales}

Collective memories, resistance and social movements

\author{
Dra. Isabel Piper ( $\left.{ }^{1}\right)$ \\ Universidad de Chile \\ Chile \\ ipiper@u.uchile.cl
}

\title{
EDITORIAL
}

En nuestras investigaciones sobre memoria colectiva hemos asumido el desafío de entenderla como una práctica social. Esto ha implicado alejarse de aquellas visiones que asumen la memoria como una facultad individual y también de aquellas que asumen los recuerdos como representaciones del pasado. Buscamos comprender los procesos sociales de construcción de memorias colectivas siempre en relación con los procesos políticos en los cuales se realiza, reflexionando en torno a los significados, imaginarios sociales y acciones políticas que contribuyen a producir.

Este ha sido el sello de quienes creamos, hace ya cinco años el, subprograma Memorias, Historias y Derechos Humanos - parta del Programa Domeyko Sociedad y Equidad - que se constituyó en un espacio de reflexión interdisciplinar en el que confluyen diversas tradiciones de pensamiento, múltiples miradas y distintos métodos de investigación.

Este cuarto número de Revista Sociedad y Equidad recoge ese mismo espíritu, es decir, el de reflexionar desde perspectivas diversas en torno a

\footnotetext{
${ }^{1}$ Doctora en Psicología Social, Universidad Autónoma de Barcelona. Académica e Investigadora de la Facultad de Ciencias Sociales de la Universidad de Chile, Departamento de Psicología. Miembro del Comité Editorial de Revista Sociedad y Equidad.
} 


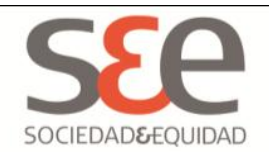

procesos de memoria colectiva lo que a su vez implica en sí mismo una acción de memoria.

Los artículos que la conforman éste número nos invitan a debatir en torno a múltiples prácticas de memoria así como su relación con movimientos de resistencia y transformación social. Nos muestran que la memoria, lejos ser huellas de un pasado remoto, son prácticas de significación de nuestras sociedades que contienen en sí mismas el pasado, el presente y el futuro.

No existen sociedades sin memoria. A través de ella vemos tanto nuestras continuidadades como nuestras transformaciones, generando múltiples significados sobre lo que somos y sobre lo que podemos ser, proyectando acciones de resistencia y contrahegemonía. Al hacer memoria nos preguntamos sobre el pasado, intentamos comprender cómo hemos llegado a ser lo que somos y lo que no somos, cuestionado de diversos modo la situación actual de nuestras sociedades.

Haciendo memoria nos enfrentamos con prácticas de dominación y de resistencia.

Los textos incluidos en este número nos hablan de algunos de estos procesos, específicamente relacionados con movimientos transformadores en el campo de los conflictos medioambientales; de la perspectiva de género en movimientos de mujeres latinoamericanas; de organizaciones indigenas de recuperación de territorio, cultura e identidad.

A su vez, nos invitan a reflexionar en torno a diversas formas de recordar presentando el caso de las memorias sonoras, es decir la resignificación del pasado y el presente a través de sonidos que servían de orientación y referencia en los campos de detención en los que los y las prosioneras permanecían con la vista vendada. La acción política tiene también distintos modos de realizarse, como es a través de su materialización en espacios urbanos; del uso de las nuevas tecnologías de la información y la comunicación (TIC); y la huelga de hambre como una herramienta que busca visibilizar el sufrimiento y desnaturalizar la represión por medio de un acto sacrificial donde los cuerpos se exponen al dolor. 